TITLE:

\title{
Predominance of cross-predation between lateral morphs in a largemouth bass and a freshwater goby.
}

$\operatorname{AUTHOR}(S)$ :

Yasugi, Masaki; Hori, Michio

\section{CITATION:}

Yasugi, Masaki ...[et al]. Predominance of cross-predation between lateral morphs in a largemouth bass and a freshwater goby.. Zoological science 2011, 28(12): 869-874

ISSUE DATE:

2011-12

URL:

http://hdl.handle.net/2433/169697

RIGHT:

(C) 2011 Zoological Society of Japan 


\section{Predominance of Cross-Predation between Lateral Morphs in a Largemouth Bass and a Freshwater Goby}

Author(s): Masaki Yasugi and Michio Hori

Source: Zoological Science, 28(12):869-874. 2011.

Published By: Zoological Society of Japan

DOI: http://dx.doi.org/10.2108/zsj.28.869

URL: http://www.bioone.org/doi/full/10.2108/zsj.28.869

BioOne (www.bioone.org) is a nonprofit, online aggregation of core research in the biological, ecological, and environmental sciences. BioOne provides a sustainable online platform for over 170 journals and books published by nonprofit societies, associations, museums, institutions, and presses.

Your use of this PDF, the BioOne Web site, and all posted and associated content indicates your acceptance of BioOne's Terms of Use, available at www.bioone.org/page/terms_of_use.

Usage of BioOne content is strictly limited to personal, educational, and non-commercial use. Commercial inquiries or rights and permissions requests should be directed to the individual publisher as copyright holder. 


\title{
Predominance of Cross-predation between Lateral Morphs in a Largemouth Bass and a Freshwater Goby
}

\author{
Masaki Yasugi ${ }^{*}$ and Michio Hori \\ Department of Zoology, Graduate School of Science, Kyoto University, \\ Sakyo, Kyoto 606-8502, Japan
}

\begin{abstract}
The predator-prey relationship between largemouth bass, Micropterus salmoides, and freshwater goby, Rhinogobius spp., in Lake Biwa, Japan, was examined with respect to their morphological antisymmetry (laterality). Largemouth bass and Rhinogobius gobies exhibited lateral dimorphism in the height of the mandible and the length of the dentary, respectively. Populations of both species were composed of both left-developed and right-developed individuals. Each predation event was categorized as either cross-predation (a predator caught prey of the opposite morph) or parallel-predation (a predator caught prey of the same morph). Stomach contents analysis revealed that cross-predation events predominated over parallel-predation. Annual sampling for eight years demonstrated that in both largemouth bass and Rhinogobius gobies, the ratio of right-developed individuals in the population fluctuated temporally around 0.5 . As the predominance of cross-predation was found in the relationship between the exotic largemouth bass and an endemic goby, the predominance may be caused by a kinematical interplay at each predation event.
\end{abstract}

Key words: antisymmetry, morphological asymmetry, laterality, predation, prey-predator relationship, Micropterus salmoides, Rhinogobius

\section{INTRODUCTION}

Laterality is defined as dimorphism in which one side of the body is structurally and/or functionally superior to the other side. In fishes that show laterality, individuals are mostly either left-biased, with well-developed left sides and mouths opening rightward (hereafter, "lefties") or the opposite (hereafter, "righties"), and populations exhibit a bimodal distribution between the two morphs; few individuals are symmetric (sensu Nakajima et al., 2004). This morphological asymmetry is categorized as antisymmetry and can be distinguished from fluctuating or directional asymmetry (Palmer and Strobeck, 1986). This type of fish laterality was first documented in the scale-eating cichlids of Lake Tanganyika, Perissodus spp. (Liem and Stewart, 1976; Hori, 1991, 1993). Subsequent research has revealed that many other fishes possess this dimorphism (Mboko et al., 1998; Seki et al., 2000; Hori et al., 2007; Nakajima et al., 2007; Takeuchi and Hori, 2008; Takeuchi et al., 2010).

This laterality can have a profound influence on predatorprey relationships. In the scale-eating cichlids, predation success differs between lateral morphs on a frequencydependent basis (Hori, 1993). The predatory behaviors of the scale-eaters correspond to their mouth morphs: individuals whose mouths open rightward (leftward) tear off scales from the left (right) side of prey fish. In this system, prey fishes are expected to be more vigilant against the dominant

\footnotetext{
${ }^{*}$ Corresponding author. Phone: $+81-75-753-4077$;

Fax : +81-75-753-4100;

E-mail: myasugi@terra.zool.kyoto-u.ac.jp

Supplemental material for this article is available online. doi:10.2108/zsj.28.869
}

morph of scale-eaters, which appears to confer higher predation success to the rare morph (Hori, 1993). In addition, the piscivorous cichlids of Lake Tanganyika exploit more prey of the opposite morph (cross-predation) than those of the same morph (parallel-predation) (Hori, 2000, 2007). Based on this observation, Hori (2007) predicted that the ratio of laterality (the proportion of righties in a population) of predators and prey would show a correlated oscillation around 0.5 . Thus, for example, if there are more righty predators than lefty ones, lefty prey should be exploited more frequently and righty prey therefore increase, eventually leading to an increase in lefty predators. The now-dominant lefty predators would reduce righty prey, which would increase lefty prey and result in righty predators dominating once again. In this context, Nakajima et al. (2004) demonstrated mathematically that, under predominance of crosspredation, dimorphism is maintained without the fixation on either only lefties or only righties. However, there were few studies on fish to relate the laterality to the predator-prey relationship, and to examine the dynamics of laterality within the relationships in a natural system (but see Takeuchi, 2008; Takeuchi et al., 2008).

The purposes of the present study are to examine the effect of laterality on predator-prey relationships, and to monitor the dynamics of the ratio of laterality within such a relationship. The largemouth bass, Micropterus salmoides (Lacepède, 1802), a North American sunfish (Centrarchidae) introduced into Japan in 1925, invaded Lake Biwa in 1970s, and mainly feeds on the Rhinogobius goby (Ministry of the Environment, Government of Japan, 2004). Previous studies have demonstrated that both of them exhibit laterality (Seki et al., 2000 for Rhinogobius goby; Nakajima et al., 2007 for the largemouth bass). We investigated the relation- 
ship between the morphs of largemouth bass collected from the field and those of Rhinogobius goby found in their stomachs, and monitored annual changes in the ratio of laterality of these two species at fixed sites of Lake Biwa.

\section{MATERIALS AND METHODS}

\section{Sampling}

For stomach content analysis, largemouth bass $(\mathrm{N}=610, \bar{X} \pm$ $\mathrm{SD}=111.6 \pm 24.7 \mathrm{~mm}$ standard length (SL)) were captured using a gill net from July to September in 2003, 2004, and 2005 at Kitakomatsu, along the west coast

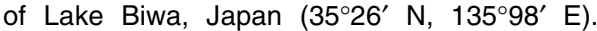
Captured largemouth bass were cooled with refrigerant for anesthetization. After they ceased respiration, $10 \%$ formalin was injected into their abdominal cavities to fix their stomach contents. Subsequently, the entire fish was preserved in $10 \%$ formalin.

Because the abundance of largemouth bass at Kitakomatsu decreased greatly in 2005 , additional fish were collected to monitor temporal changes in the ratio of laterality. These fish $(\mathrm{N}=575, \bar{X} \pm \mathrm{SD}=134.6 \pm 26.2 \mathrm{~mm} \mathrm{SL})$ were collected using a gill net at Imajuku, $15 \mathrm{~km}$ south of Kitakomatsu $\left(35^{\circ} 09^{\prime} \mathrm{N}, 135^{\circ} 56^{\prime} \mathrm{E}\right)$ from 2004 to 2010. Rhinogobius gobies were collected from 2003 to 2010 using a fixed net at Imajuku $(\mathrm{N}=442, \bar{X} \pm \mathrm{SD}=34.6 \pm 2.7 \mathrm{~mm} \mathrm{SL})$ and in 2004 and 2005 using a hand net at Kitakomatsu $(\mathrm{N}=182, \bar{X} \pm \mathrm{SD}=32.8 \pm 3.0 \mathrm{~mm} \mathrm{SL})$. Gobies were preserved in $10 \%$ formalin.

Two species of Rhinogobius gobies inhabit Lake Biwa, type OR and BW, which remain unnamed (see Takahashi and Okazaki, 2002). The species are distinguished by the portion of their bodies that are scaled; however, in this study, they could not be differentiated, as the scales and skin of specimens swallowed by largemouth bass were often digested. In the field, most gobies collected by hand net at Kitakomatsu were Rhinogobius sp. OR, whereas those collected by fixed net at Imajuku were Rhinogobius sp. BW. Here, we treat these species collectively as Rhinogobius spp.

These treatments were performed in accordance with the Regulations on Animal Experimentation at Kyoto University.

\section{Stomach content analysis}

The stomach contents of all largemouth bass specimens at Kitakomatsu were identified to the species level to the extent possible. Stomach content data were analyzed using the numerical method, where the number of prey individuals in every food category is expressed as the percentage of total individuals in all food categories in all stomachs (Hyslop, 1980; Ayoade and Ikulala, 2007).

\section{Measurement of morphological asymmetry in lower jaws}

The lateral asymmetry of largemouth bass and Rhinogobius gobies was measured to identify their lateral morphs. The lateral morph of largemouth bass can be detected by head inclination, as described by Nakajima et al. (2007).
Head inclination is defined as the angle between the ventral sagittal lines of the neurocranium and vertebrae; more specifically, the ventral sagittal lines from the tip of the prominence of the parasphenoid to the posterior end of the occipital bone and from that point to the posterior end of the third vertebra. We also measured the height of the left and right mandible posterior ends (HMPEs, Fig. 1A, B) after Hori et al. (2007). Recent studies have indicated that this trait is the key for the evaluation of laterality (Hori et al., 2007; Takeuchi and Hori, 2008). The HMPEs were only measured for largemouth bass from Kitakomatsu that contained Rhinogobius gobies in their stom-
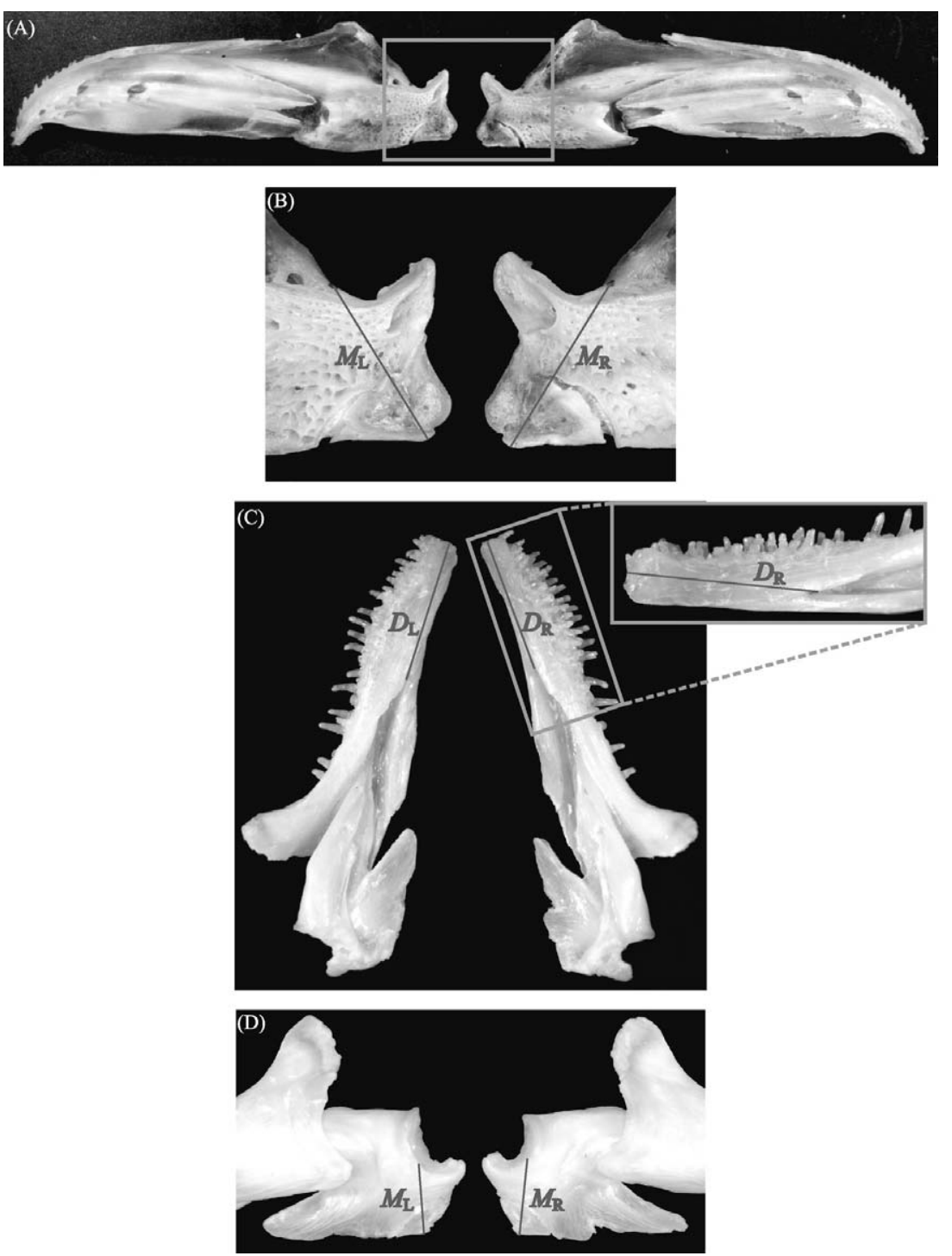

Fig. 1. Data points for measuring asymmetry in the lower jaws of largemouth bass, Micropterus salmoides (A, B), and the Rhinogobius goby (C, D). (A) Outer lateral view of entire lower jaw of the largemouth bass. (B) Enlarged area showing mandible posterior ends (MPEs) of largemouth bass. The area is indicated by a box in (A). $M_{L}$ and $M_{\mathrm{R}}$ indicate the heights of the left and right MPE, respectively. The height of the MPE is the distance between the bottom of the suspensoriad articulation facet of the anguloarticular and the ventral end of the retroarticular process (Hori et al., 2007). (C) Dorsal view of the entire lower jaw of the Rhinogobius goby. In this paper, we defined the length of the dentary as the distance between the tip and the anterior edge of the Meckelian fossa. $D_{\llcorner}$and $D_{R}$ indicate the length of the left and right dentary, respectively. The upper right box displays the inner lateral view of $D_{\mathrm{R}}$. (D) Outer lateral view of latter halves of lower jaws showing MPEs of the Rhinogobius goby. $M_{\mathrm{L}}$ and $M_{\mathrm{R}}$ indicate the height of the left and right MPE, respectively. 
achs. For bass specimens in 2005, both head inclination (following Nakajima et al., 2007 and Takeuchi et al., 2010) and HMPEs were measured to examine the consistency of lateral (left-right) differences for these two traits.

Rhinogobius gobies exhibit morphological antisymmetry in the length of their lower jaws (Seki et al., 2000); however, we also measured dentary length, i.e., the distance between the tip and the Meckelian fossa of the dentary (Fig. 1C), as the small and thin mandibles of gobies were easily deformed by digestion and were difficult to measure. This dentary length was measured for gobies found in the stomach of largemouth bass, but overly digested or broken specimens were not used for morphological measurements. Nine large Rhinogobius individuals collected from the field were used for measuring dentary length, HMPEs (Fig. 1D), and head inclination to examine the consistency among left-right differences of these three traits.

All morphological measurements were performed under a digital microscope (VHX-100, Keyence Ltd.) to the nearest $0.01 \mathrm{~mm}$ and $0.1^{\circ}$ for the traits of lower jaw and head inclination, respectively. For measurements of HMPEs and the dentary, the lower jaws were removed and soaked in sodium hypochlorite $(8.5-13.5 \% \mathrm{Cl})$ diluted twice with water to dissolve skin and muscle. Every specimen was measured three separate times. To reduce measurement error, the medians of the three measurements were used for an index of asymmetry (IAS). Values of measurement error were very small (ANOVA: HMPE of largemouth bass, $F_{131,264}=3068.80, P<0.001$; HMPE of Rhinogobius goby, $F_{15,32}=21.46, P<0.001$; dentary of Rhinogobius goby, $\left.F_{161,324}=22942.39, P<0.001\right)$. The IAS of the HMPE was calculated as $\left[2 \times\left(M_{\mathrm{R}}-M_{\mathrm{L}}\right) /\left(M_{\mathrm{R}}+M_{\mathrm{L}}\right)\right] \times 100$, where $M_{\mathrm{R}}$ and $M\llcorner$ were the medians of the right and left HMPE, respectively (Fig. 1B, D). Individuals with positive IAS values of HMPE, i.e., the right HMPE was larger than the left one, were defined as "righties," and those with negative IAS values were defined as "lefties" (Hori et al., 2007). The IAS of the dentary was calculated as $\left[2 \times\left(D_{\mathrm{R}}-\right.\right.$ $\left.\left.D_{\mathrm{L}}\right) /\left(D_{\mathrm{R}}+D_{\mathrm{L}}\right)\right] \times 100$, where $D_{\mathrm{R}}$ and $D_{\mathrm{L}}$ were the medians of the right and left dentary, respectively (Fig. 1C). For the measurement of head inclination, extra skin and muscles were removed, and the cranial bone and vertebra were exposed. The medians of three measurements were used to reduce measurement error (ANOVA: largemouth bass, $F_{16,34}=5498.03, P<0.001$; Rhinogobius goby, $\left.F_{7,16}=3106.19, P<0.001\right)$.

Left-right differences in bilateral morphological characters can be classified as fluctuating asymmetry, directional asymmetry, or antisymmetry (Palmer and Strobeck, 1986). To define the antisymmetry of the traits measured here, we fit the following three models to the distribution of their IAS values: (a) normal distribution with mean 0 and SD from the data, which assumed fluctuating asymmetry (FA-model), (b) normal distribution with both mean $(\mu)$ and SD from the data, which assumed directional asymmetry (DA-model), and (c) asymmetric bimodal distribution composed of an unequally weighted mixture of two normal distributions with means $( \pm \mu)$, which assumed antisymmetry (AS-model). In the ASmodel, the normal distribution took on means $+\mu$ and $-\mu$, corresponding to that of righties and lefties, respectively. The mean, SD, and ratio of righties and lefties in the AS-model were calculated using maximum likelihood estimation. To judge the best fit model, we calculated Akaike's Information Criteria $(\mathrm{AIC})$ values of the three models using their maximized likelihood values and degrees of freedom. The model with the lowest AIC was considered to be the distribution of each IAS. The deviance of each IAS from fluctuating asymmetry was examined using the Shapiro-Wilk test. These analyses were performed using the IAS of the HMPEs of largemouth bass and the dentary length of prey Rhinogobius gobies.

\section{Relationship between predator morph and swallowed prey morph}

To examine the relationship between predator morph and swallowed prey morph, we constructed a generalized linear mixed model (GLMM; Schall, 1991) with lateral morph of prey as the dependent variable, assuming the binomial error distribution and a logit link function. In this model, the lateral morph of the predator, sampling year, and their interaction were included as fixed factors. In addition, the individual identity of predators was included as a random factor to avoid pseudo-replication, as some predators $(18.2 \%)$ contained plural prey individuals in their stomachs (e.g. Hurlbert, 1984; Russell et al., 2002). The interactions between factors were deleted from the model when they explained no variance.

\section{Temporal changes in the ratio of the lateral morph of predators} and prey in natural populations

To investigate temporal changes in the ratio of the lateral morph, we identified the morphs of largemouth bass and Rhinogobius gobies collected from the field based on their head inclination. Ratios of laterality in each species were monitored in every summer, and the periodicity in the ratio of laterality was analyzed using the Fourier transform (see Supplementary Text S1).

Statistical analyses were performed using $R$ version 2.12.1 ( $R$ Development Core Team, 2010). IAS model fitting and GLMM required the packages stats 4 and Ime4 version 0.999375-37 (Bates and Maechler, 2010), respectively.

\section{RESULTS}

\section{Stomach content analysis}

A total of 204, 257, and 132 largemouth bass collected at Kitakomatsu were analyzed in 2003, 2004, and 2005, respectively. Of the total stomach contents, $30-40 \%$ was composed of fish, and the remainder was shrimp. Over the three years, the most exploited fish species was the freshwater goby, Rhinogobius spp. (Table 1).

\section{Morphological asymmetry in the lower jaws of the pred- ator and its prey}

The IASs of both the HMPEs of largemouth bass and the dentary length of Rhinogobius gobies significantly deviated from normal distributions and exhibited the best fit to the models of bimodal distribution (Table 2 and Fig. 2). These results indicated that the left-right differences in both morphological traits reflect antisymmetry. Lefty largemouth bass had rightward head inclinations, whereas righty largemouth bass had leftward head inclinations $(N=17)$. In Rhinogobius gobies, large specimens showed perfectly inverse relationship in the sign of IAS between HMPE and dentary length, i.e., lefty individuals (negative IAS of HMPE)

Table 1. Prey species found in the stomachs of largemouth bass. $\% \mathrm{~N}$ indicates values calculated using the numerical method.

\begin{tabular}{|c|c|c|c|c|c|}
\hline \multirow{2}{*}{ Prey items } & & & \multicolumn{3}{|c|}{ Number $(\% \mathrm{~N})$} \\
\hline & & & 2003 & 2004 & 2005 \\
\hline \multirow[t]{4}{*}{ Fish } & Gobiidae & Rhinogobius spp. & $90(37.5)$ & $59(16.6)$ & 35 (15.5) \\
\hline & & Tridentiger brevispinis & $4(1.7)$ & $8(2.2)$ & $6(2.7)$ \\
\hline & Osmeridae & Plecoglossus altivelis & $0(0.0)$ & $15(4.2)$ & $1(0.4)$ \\
\hline & Other teleost & unidentified & $1(0.4)$ & $52(14.6)$ & $27(11.9)$ \\
\hline Shrimp & Palaemonidae & $\begin{array}{l}\text { Palaemon paucidens and } \\
\text { Macrobrachium nipponense }\end{array}$ & $144(60.0)$ & $175(49.2)$ & $141(62.4)$ \\
\hline \multirow[t]{4}{*}{ Other animals } & & insects, snails, etc. & $1(0.4)$ & 47 (13.2) & $16(7.1)$ \\
\hline & & Total preys & $240(100)$ & $356(100)$ & $226(100)$ \\
\hline & & Total predators & 204 & 257 & 132 \\
\hline & & Empty predators & 60 & 54 & 10 \\
\hline
\end{tabular}


Table 2. Results of three model fittings and Shapiro-Wilk tests for the distribution of the IAS in largemouth bass and Rhinogobius goby eaten by them. Models assumed each of three patterns for possible distributions of the bilateral traits. The lowest AIC value for each species is indicated with a bold letter.

\begin{tabular}{lccccccr}
\hline \multirow{2}{*}{ Species Name } & $N$ & \multicolumn{3}{c}{ AIC } & & \multicolumn{2}{c}{ Shapiro-Wilk test } \\
\cline { 3 - 4 } \cline { 7 - 8 } & & FA-model & DA-model & AS-model & & $W$ & $P$ \\
\hline largemouth bass & 66 & 325.51 & 318.71 & 251.06 & & 0.859 & $<0.001$ \\
Rhinogobius spp. & 81 & 453.12 & 453.10 & 426.29 & & 0.948 & 0.002 \\
\hline
\end{tabular}

(A)

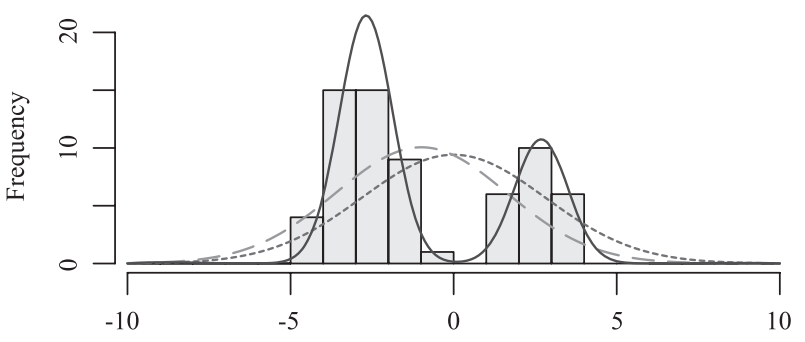

Index of asymmetry in the height of mandible posterior ends of largemouth bass

(B)

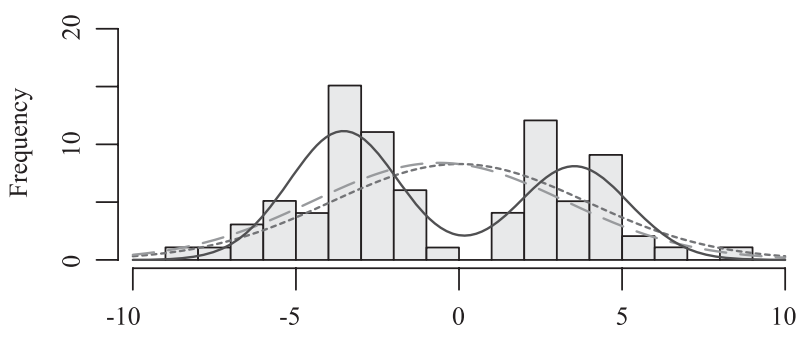

Index of asymmetry in the length of dentary of Rhinogobius goby

Fig. 2. Frequency distributions of the IAS of the height of MPE in largemouth bass (A) and the length of the dentary in Rhinogobius goby eaten by bass (B). Lines over each histogram indicate the probability distributions of three models fitted to that of the IAS (dotted line, FA-model; dashed line, DA-model; solid line, AS-model).

showed positive IAS of dentary length and rightward head inclination, and righty individuals (positive IAS of HMPE) showed negative IAS of dentary length and leftward head inclination $(\mathrm{N}=9)$.

\section{Relationship between predator morph and swallowed prey morph}

The predator-prey relationship between largemouth bass and Rhinogobius gobies exhibited a significant bias toward cross-predation (Tables 3 and 4). In the GLMM analysis, the ratio of SL, sampling year, and their interaction did not significantly affect the prey morph. The odds ratio calculated from the coefficient of the GLMM analysis was 6.6 (95\% confidence interval: 2.1-20.2), indicating that cross-predation occurred 6.6 times as frequently as parallelpredation.
Table 3. Relationship between morphs of largemouth bass and morphs of Rhinogobius goby eaten by them.

\begin{tabular}{|c|c|c|c|c|c|c|c|}
\hline \multirow{3}{*}{$\begin{array}{l}\text { Laterality of } \\
\text { largemouth bass }\end{array}$} & & \multicolumn{6}{|c|}{ Laterality of Rhinogobius spp. } \\
\hline & \multirow[t]{2}{*}{ Year } & \multicolumn{2}{|c|}{2003} & \multicolumn{2}{|c|}{2004} & \multicolumn{2}{|c|}{2005} \\
\hline & & Lefty & Righty & Lefty & Righty & Lefty & Righty \\
\hline Lefty & & 8 & 16 & 4 & 11 & 3 & 10 \\
\hline Righty & & 6 & 3 & 8 & 3 & 5 & 4 \\
\hline
\end{tabular}

Table 4. Results of GLMM analysis for the morphs of Rhinogobius goby eaten by largemouth bass.

\begin{tabular}{lccrr}
\hline \multicolumn{1}{c}{ Variable } & Coefficient & S.E. & \multicolumn{1}{c}{$z$} & \multicolumn{1}{c}{$P$} \\
\hline Intercept & 0.896 & 0.450 & 1.988 & 0.046 \\
Predator Laterality [Righty] & -1.891 & 0.569 & -3.318 & $<0.001$ \\
Sampling year [2004] & 0.098 & 0.639 & 0.154 & 0.877 \\
Sampling year [2005] & 0.620 & 0.693 & 0.894 & 0.371 \\
\hline
\end{tabular}

Temporal changes in the ratio of the lateral morph of predators and prey in natural populations

At Imajuku and Kitakomatsu, both lateral morphs of the largemouth bass and of the Rhinogobius goby were maintained for several years (Fig. 3, Supplementary Table S1). Their ratios of laterality temporally changed around a value of 0.5 , and the ratios only significantly differed between the two locations for Rhinogobius gobies in 2004 (two-sample test for equality of proportions: $\chi^{2}=3.994, P=0.045$ ). Fourier transform did not detect any significant period of oscillation in the ratios of either species at Imajuku.

\section{DISCUSSION}

In the predator-prey relationship between largemouth bass and Rhinogobius goby, cross-predation predominated over parallel-predation. This result suggests that the combination of the lateral morphs of predators and prey affects predation success. Cross-predation also dominates the predator-prey relationship between Tanganyikan piscivorous cichlids and its prey cichlids (Hori, 2000, 2007). Almost all Tanganyikan cichlids have evolved and speciated within the lake (Poll, 1986; Nishida, 1997), which may indicate that the predator-prey relationships affected by laterality have developed through the long period of their coexistence. In contrast to the community of cichlids, however, the largemouth bass is an exotic predator that was introduced into Lake Biwa in the 1970s (Ministry of the Environment of Japan, 2004), and only a short time (< 40 years) has passed since it first encountered the indigenous prey goby. Here, we have demonstrated that cross-predation can dominate in even a relatively new predator-prey relationship, indicating that the predominance should be generated from a kinematic causation in any predator-prey interplay as long as they have the laterality.

We hypothesize that the predominance of cross-predation occurs based on the combination of dominant side between lateralized predators and preys. Every predation event results from the interplay of an attack of a predator and an evasive reaction of a target prey. Therefore, it is necessary to compare the nature of these behaviors between the lateral morphs of both predator and prey. Nakajima et al. (2007) demonstrated that when largemouth bass chased a swiftly pulled lure and attacked it from behind, the righty 


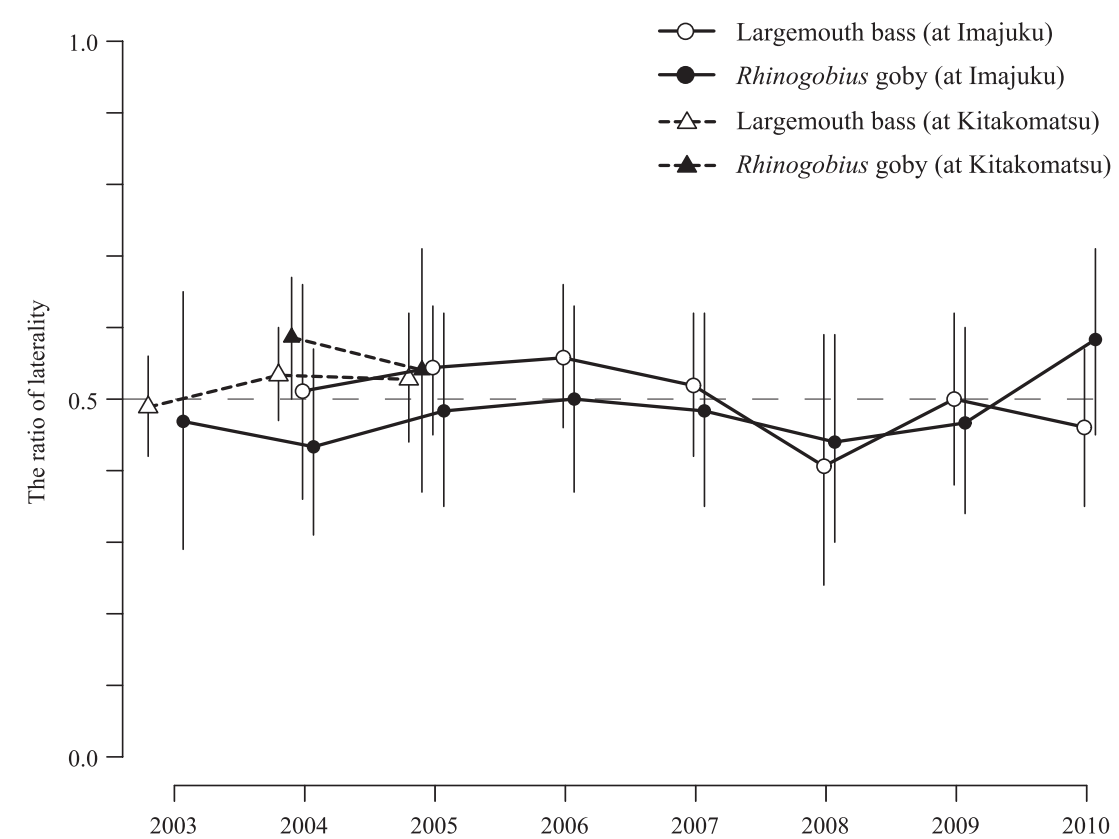

Fig. 3. Annual changes in the ratio of laterality in the largemouth bass and Rhinogobius goby at Imajuku and Kitakomatsu in Lake Biwa from 2003 to 2010. Vertical bars on each plot indicate $95 \%$ confidence intervals.

morph made counterclockwise attacks on the lure (it rushed roundly to grasp the lure from the diagonally backward right) more frequently than clockwise attacks. Other predator, such as the Tanganyikan shrimp-eating cichlid Neolamprologus fasciatus, also exhibits behavioral laterality in attacking behavior based on morph: righty individuals show more leftward hunting, whereas lefties show more rightward hunting (Takeuchi and Hori, 2008). Rhinogobius gobies may also have a similar bias in evasive reaction. If so, the predominance of cross-predation means that one type of morph, e.g., the lefty goby, is certain to escape more easily when being attacked from diagonally backward left (clockwise), which is adopted mainly by lefty predators, than when being attacked counterclockwise from primarily righty predators. This advantage of prey gained by a specific side may result from differences in the ability to detect the approach of a predator from the left and right side. Alternatively, the goby may have the favorite and good use of direction in its escape as well as the directional bias in the attack of the largemouth bass. Lateralization in the resting posture of the goby (Seki et al., 2000) may relate to these left-right differences. In either case, it can be said that cross-predation occurs more frequently than parallel-predation by a kinematic mechanism that depends on the combination of lateralized predators and prey. To test this hypothesis as the mechanism for the predominance of cross-predation, we need a detailed experiment for observing the interactions between the attack of predator and the evasive behavior of prey with respect to their laterality.

This study also documented the dynamics of laterality under the predominance of cross-predation. Our results supported the predictions of Hori (2007) that laterality of the predator and prey is dynamically maintained, with the ratios of laterality changing around 0.5 . This pattern was observed at both Imajuku and Kitakomatsu, although the ratio of lateral morphs and the phase of dynamics appeared to differ between locations. Although the relationship between the ratio of laterality of largemouth bass and that of Rhinogobius goby could not be analyzed statistically, the ratios of both species exhibited similar patterns at Imajuku, suggesting that their dynamics are correlated. However, this correlation may be not so intimate, as largemouth bass are opportunist and Rhinogobius goby accounted for only less than $40 \%$ of stomach contents of bass in summer. Their correlation can be affected greatly by the interaction with shrimps (Palaemon paucidens and Macrobrachium nipponense), which largemouth bass largely exploited. The laterality of a fresh water shrimp (Neocaridina denticulata) was already shown by Takeuchi et al. (2008), and a dynamics of lateral morphs between shrimp-eating cichlid fish (Neolamprologus spp.) and their prey shrimp (Limnocaridina latipes) was demonstrated by Takeuchi (2008), though in these system parallel-predation was predominant. Additional longterm research is necessary to examine the correlation of laterality among largemouth bass, Rhinogobius goby and shrimps.

\section{ACKNOWLEDGMENTS}

We thank T. Komiya and M. Sasabe for their assistance in sampling largemouth bass and $\mathrm{S}$. Takahashi for help with statistical analysis. We also thank Y. Takeuchi, D. Takahashi, K. Watanabe, T. Sota, H. Toju, and other members of the Laboratory of Animal Ecology, Graduate School of Science, Kyoto University, for their assistance in sampling Rhinogobius gobies and their support for the entire research. This study was financially supported in part by a Grant for Biodiversity Research of the 21st Century COE Program (A14), Grants-in-Aid for Scientific Research in Priority Areas (14087203), and the Global COE Program "Formation of a Strategic Base for Biodiversity and Evolutionary Research: from Genome to Ecosystem," Ministry of Education, Culture, Sports, Science and Technology (MEXT), Japan.

\section{REFERENCES}

Ayoade AA, Ikulala AOO (2007) Length weight relationship, condition factor and stomach contents of Hemichromis bimaculatus, Sarotherodon melanotheron and Chromidotilapia guentheri (Perciformes : Cichlidae) in Eleiyele Lake, Southwestern Nigeria. Rev Biol Trop 55: 969-977

Hori M (1991) Feeding relationships among cichlid fishes in Lake Tanganyika: effect of intra- and interspecific variations of feeding behavior on their coexistence. INTECOL Bull 19: 89-102

Hori M (1993) Frequency-dependent natural selection in the handedness of scale-eating cichlid fish. Science 260: 216-219

Hori M (2000) Gunshuu no tayousei to anteika-kikou (The diversities and stabilizing mechanism of communities). In "GunshuuSeitaigaku no Genzai (Current Community Ecology)" Ed by $\mathrm{H}$ Sato, T Yamamoto, Kyoto University Press, Kyoto, pp 257-283

Hori M (2007) Tanganyikako no gyorui gunshu to sayusei no doutai (Fish community in Lake Tanganyika and the dynamics of laterality). In "Seitai to Kankyou (Ecology and Environment)" Ed by $T$ Matsumoto, M Hasegawa, Baifukan, Tokyo, pp 51-95 
Hori M, Ochi H, Kohda M (2007) Inheritance pattern of lateral dimorphism in two cichlids (a scale eater, Perissodus microlepis, and an herbivore, Neolamprologus moorii) in Lake Tanganyika. Zool Sci 24: 486-492

Hurlbert S (1984) Pseudoreplication and the design of ecological field experiments. Ecol Monogr 54: 187-211

Hyslop EJ (1980) Stomach contents analysis - a review of methods and their application. J Fish Biol 17: 411-429

Liem KF, Stewart DJ (1976) Evolution of the scale-eating cichlid fishes of Lake Tanganyika: a generic revision with a description of a new species. Bull Mus Comp Zool 147: 319-350

Mboko SK, Kohda M, Hori M (1998) Asymmetry of mouth-opening of a small herbivorous cichlid fish Telmatochromis temporalis in Lake Tanganyika. Zool Sci 15: 405-408

Ministry of the Environment, Government of Japan (2004) Black bass . blue gill ga zairai seibutsu gunshuu oyobi seitaikei ni ataeru eikyou to taisaku. Japan Wildlife Research Center, Tokyo

Nakajima M, Matsuda H, Hori M (2004) Persistence and fluctuation of lateral dimorphism in fishes. Am Nat 163: 692-698

Nakajima M, Yodo T, Katano O (2007) Righty fish are hooked on the right side of their mouths - observations from an angling experiment with largemouth bass, Micropterus salmoides. Zool Sci 24: 855-859

Nishida M (1997) Phylogenetic relationships and evolution of Tanganyikan cichlids: A molecular perspective. In "Fish Communities in Lake Tanganyika" Ed by H Kawanabe, M Hori, M Nagoshi, Kyoto University Press, Kyoto, pp 3-23

Palmer AR, Strobeck C (1986) Fluctuating asymmetry - measurement, analysis, patterns. Annu Rev Ecol Syst 17: 391-421

Poll M (1986) Classification des cichlidae du lac Tangyanika, tribus, genres et especes. Academie Royale de Belgigue Memoires de la Classes Des Sciences, Collection in $-8^{\circ}-2$ Serie, T. XLV -
Fascicule 2, Academie Royale de Belgique, Bruxelles, pp 1-163

Russell AF, Clutton-Brock TH, Brotherton PNM, Sharpe LL, Mcilrath GM, Dalerum FD, Cameron EZ, Barnard JA (2002) Factors affecting pup growth and survival in co-operatively breeding meerkats Suricata suricatta. J Anim Ecol 71: 700-709

Schall R (1991) Estimation in generalized linear-models with random effects. Biometrika 78: 719-727

Seki S, Kohda M, Hori M (2000) Asymmetry of mouth morph of a freshwater goby, Rhinogobius flumineus. Zool Sci 17: 13211325

Takahashi S, Hori M (1994) Unstable evolutionarily stable strategy and oscillation - a model of lateral asymmetry in scale-eating cichlids. Am Nat 144: 1001-1020

Takahashi S, Okazaki T (2002) A new lentic form of the "yoshinobori" species complex, Rhinogobius spp. from Lake Biwa, Japan, compared with lake-river migrating Rhinogobius sp OR. Ichthyol Res 49: 333-339

Takeuchi $Y$ (2008) Dynamics of laterality in shrimp-eating cichlids in Lake Tanganyika. Ph. D. Thesis, Kyoto University, Kyoto

Takeuchi Y, Hori M (2008) Behavioural laterality in the shrimp-eating cichlid fish, Neolamprologus fasciatus, in Lake Tanganyika. Anim Behav 75: 1359-1366

Takeuchi Y, Tobo S, Hori M (2008) Morphological Asymmetry of the Abdomen and Behavioral Laterality in Atyid Shrimps. Zool Sci 25: 355-363

Takeuchi Y, Hori M, Myint O, Kohda M (2010) Lateral bias of agonistic responses to mirror images and morphological asymmetry in the Siamese fighting fish (Betta splendens). Behav Brain Res 208: $106-111$

(Received March 30, 2011 / Accepted May 16, 2011) 